\title{
Dendritic polyphenylazomethines: Synthesis, structure, and metal-assembling function*
}

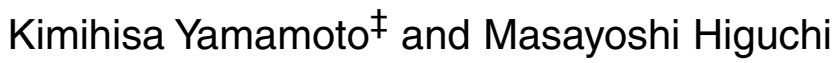 \\ Department of Chemistry, Faculty of Science \& Technology, Keio University, \\ Yokohama 223-8522, Japan
}

\begin{abstract}
Dendritic polyphenylazomethines (DPAs) were synthesized as novel topological polymer ligands with $\pi$-conjugated structures by the convergent method via dehydration of aromatic ketones with aromatic amines in the presence of $\mathrm{TiCl}_{4}$. DPA G4 molecules are revealed to have a sphere-like structure with a $2.3-\mathrm{nm}$ diameter and are regularly assembled without deformation of the molecule on a plate as observed by means of gel permeation chromatography (GPC), molecular modeling, transmission electron microscopy (TEM), atomic force microscopy (AFM), and $\pi$-A measurements. The stepwise radial complexation in DPAs with $\mathrm{SnCl}_{2}$ was observed as a stepwise shift in the isosbestic point in the UV-vis spectra. The number of added equivalents of $\mathrm{SnCl}_{2}$ required to induce a shift was in agreement with the number of imine groups present in the different shells of the DPAs. These spectral changes suggest that the complexation is proceeding in a stepwise fashion from the core imines to the terminal imines of the DPAs, which was further supported by shell-selective reduction (SSR) of the imines.
\end{abstract}

\section{INTRODUCTION}

With the development of nanoscience and nanotechnology, organic-metallic hybrid nanomaterials have received much attention for use in electronic, photonic, or magnetic nanodevices, or catalysts. The chemical and electrochemical interactions between organic polymers and metal ions/clusters in the hybrid materials are expected to enhance their properties and cause novel functions [1]. However, metal ions are randomly complexed with the coordination sites of linear polymers, because the conventional linear polymers have a "spaghetti-like" flexible structure with various molecular weights. While it is essential to control the number and position of metal ions in the hybrid materials, it is quite difficult when using linear polymers. In order to solve this problem, we focused on dendritic $\pi$-conjugated polymer ligands as novel topological polymer ligands with a single molecular weight and a single structure. Dendrimers are perfectly branched polymers with successive shells of branch units surrounding a central core [2]. Their tree-like topologies cause gradients in the branch density from the interior to the exterior, which direct the transfer of charge and energy from the dendrimer periphery to its core [3]. In addition, dendrimers having coordination sites can trap many metal ions or metal clusters within the void in the dendrimers [4]. Therefore, dendrimers are attractive organic polymers in organic-metallic hybrid materials.

Polyphenylazomethines (PPAs) are $\pi$-conjugated polymers with high thermal stability, good mechanical strength, meltability, and fiber-forming properties, and are generally synthesized via dehydra-

\footnotetext{
*Lecture presented at the symposium "Recent advances in high performance polymers: A symposium in honour of Allan Hay" as part of the $39^{\text {th }}$ IUPAC Congress and $86^{\text {th }}$ Conference of the Canadian Society for Chemistry: Chemistry at the Interfaces, Ottawa, Canada, 10-15 August 2003. Other Congress presentations are published in this issue, pp. 1295-1603.

ॠCorresponding author
} 
tion of aromatic aldehydes/ketones with aromatic amines [5,6]. Their insolubility in organic solvents limits their processing and makes the understanding of their structures difficult, but introduction of novel topological structures is expected to enhance their solubilities due to the decrease in molecular stacking. Anyway, many coordination sites of PPAs are attractive for constructing novel hybrid materials. We herein describe the syntheses of novel $\pi$-conjugated nanosupramolecules, dendritic polyphenylazomethines (DPAs), and their structures, controlled metal-assembling, and regular polymer-assembling [7].

\section{SYNTHESIS OF DPAS}

$p$-Toluenesulfonic acid (PTS) is often used as an efficient catalyst in the synthesis of PPAs via the dehydration of amines with aldehydes, but is not useful in the dehydration of aromatic amines with aromatic ketones. This is because the electrophilicity of the carbonyl carbon in the aromatic ketones is much lower than that in aldehydes. On the other hand, $\mathrm{TiCl}_{4}$ is a strong Lewis acid and acts as an effective dehydration agent. This dehydration is known to proceed via metathesis of benzophenone with a $\mathrm{Ti}=\mathrm{N}$ compound, which is formed by the reaction of aniline with $\mathrm{TiCl}_{4}$ [8]. Moreover, PTS is not suitable in such multistep syntheses such as dendrimer preparation, because the readily formed imine bonds can possibly be hydrolyzed due to an equilibrium reaction. $\mathrm{TiCl}_{4}$ is a good agent for this synthesis, because the dehydration using $\mathrm{TiCl}_{4}$ is irreversible.

In the presence of $\mathrm{TiCl}_{4}$ and 1,4-diazabicyclo[2.2.2] octane (DABCO), (DPAs G1, G2, G3, and $\mathrm{G} 4$, designated as GX, where $\mathrm{X}$ is the generation number) were synthesized by the convergent method (Scheme 1). DPA dendron G2 was formed via the dehydration of benzophenone with $4,4^{\prime}$-diaminobenzophenone (1) and was isolated by silica gel column chromatography in $48 \%$ yield. A large excess of benzophenone for $\mathbf{1}$ was used in this reaction in order to prevent undesirable dehydration between two molecules of $\mathbf{1}$, which lowers the yield of the dendron. Similarly, DPA dendrons G3 and G4 were obtained in 64 and $20 \%$ yields by dehydration of the dendrons G2 and G3 with 1, respectively. DPAs G1-4 were synthesized by dehydration of benzophenone, the dendrons G2, G3, and G4 with $p$-phenylenediamine and were isolated in $91,62,45$, and $31 \%$ yields, respectively. DPAs and the dendrons were identified as a single molecule by mass spectrometry (MS), NMR, infrared (IR), gel permeation chromatography (GPC), and elemental analysis (Fig. 1).

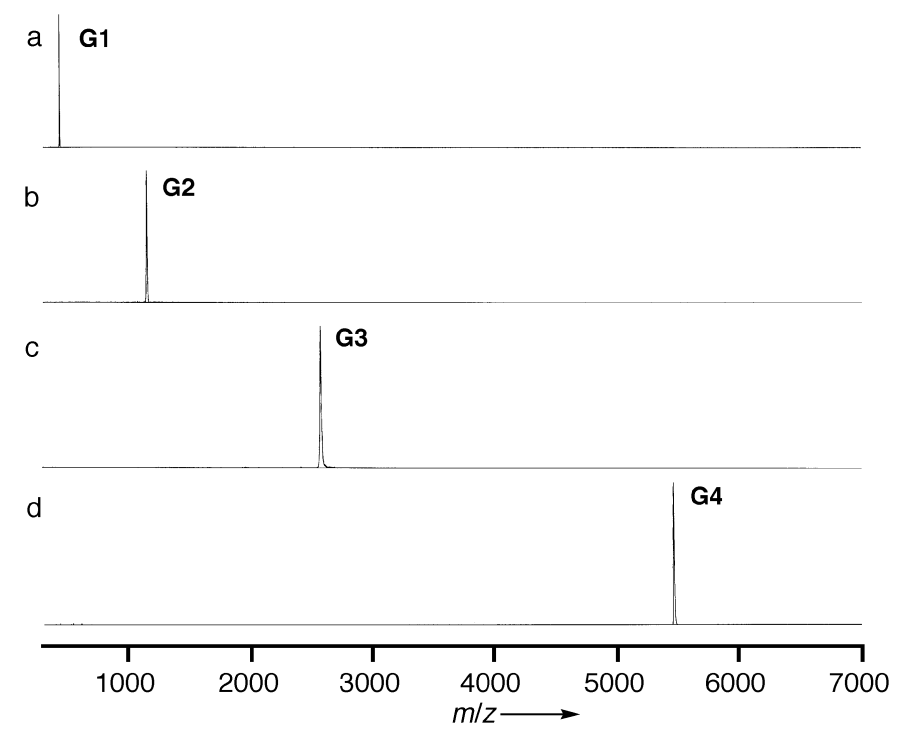

Fig. 1 MALDI-TOF-MS spectrum of DPA G1-4 (DPA G4: calculated $5451.26[\mathrm{M}+\mathrm{H}]^{+}$, found 5451.48). 


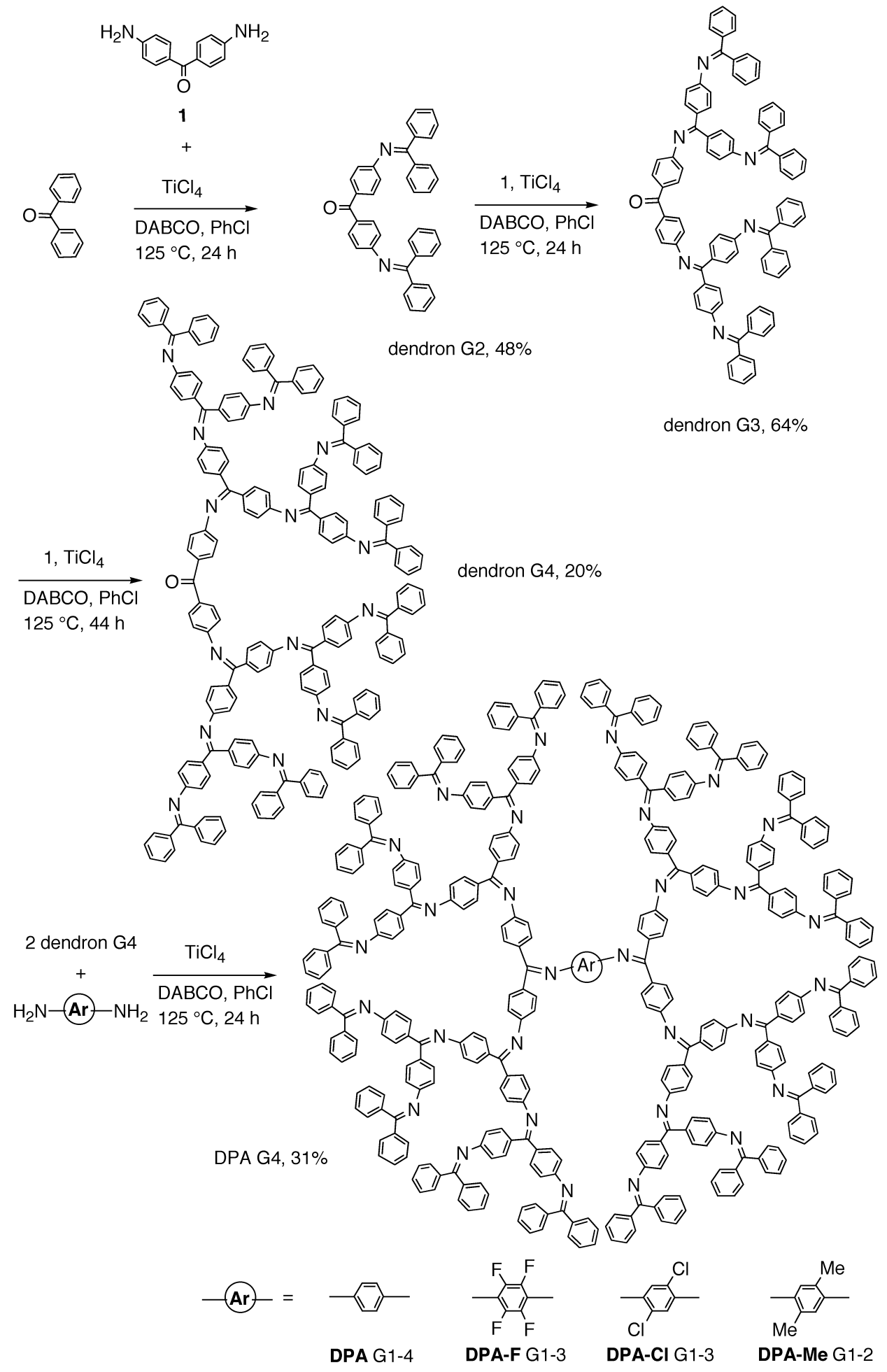

Scheme 1. Convergent synthesis of DPA. 


\section{MOLECULAR STRUCTURES OF DPAS}

The conventional PPAs with a linear structure have very low solubility. On the other hand, the obtained DPAs show high solubility for the common solvents such as chloroform, THF, or DMSO. The high solubility enabled the structural studies, investigating the complexation behavior, and the polymer assembling on a plate. The structural studies were performed by NMR, X-ray crystal analysis, and molecular modeling. The ${ }^{1} \mathrm{H}$ NMR spectra of DPAs G1-3 support the symmetrical structure of the DPAs: a singlet peak attributed to the four protons of the core phenyl ring was observed at 6.6-6.3 ppm (Figs. 2a-c). On the other hand, a singlet peak was not observed in the spectrum of DPA G4, because the conformation of the core imines is fixed by the bulky dendrons (Fig. 2d). Therefore, a broad peak attributed to the four protons of the core appeared at $6.26 \mathrm{ppm}$ in the spectrum of DPA G4 at high temperature (Fig. 2f). The appearance of this peak is due to the slight conformational exchange of the core imines in DPA G4, which was also supported by the comparison with the sharp peak in the core of DPA G3 at $130{ }^{\circ} \mathrm{C}$ (Fig. 2e).

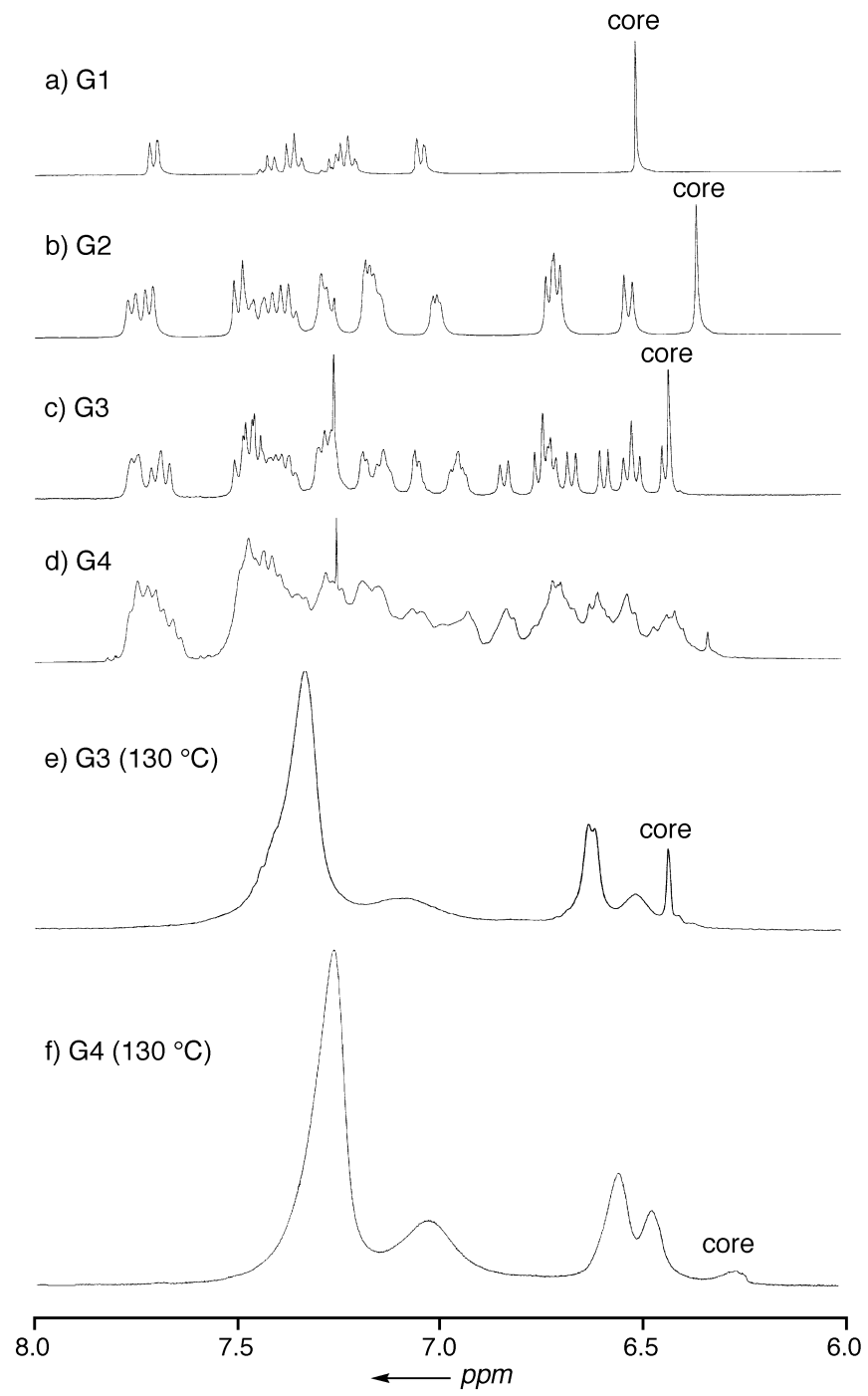

Fig. $2{ }^{1} \mathrm{H}$ NMR spectra of (a-d) DPAs G1-4 in $\mathrm{CDCl}_{3}$ at $30^{\circ} \mathrm{C}$, and those of DPAs (e) G3 and (f) G4 in DMSO- $d_{6}$ at $130{ }^{\circ} \mathrm{C}$. 
The molecular structure was directly determined by X-ray crystal analysis. Crystals of DPA G2 were obtained by slow vapor diffusion of methanol into a chlorobenzene solution of DPA G2. The crystal structure gives us three types of important information about the conformations of DPA. (1) DPA G2 has a centrosymmetrical structure, and (2) conformational patterns among the three phenyl rings connected to the imines were observed as follows. Phenyl rings connected to nitrogen of the imines $(N$-connected phenyl rings) are perpendicular to the imine bond, and the angle is twisted about $30-40^{\circ}$ by steric hindrance. In the two phenyl rings connected to carbon of the imines ( $C$-connected phenyl rings), the trans ones for the $\mathrm{N}$-connected phenyl ring are parallel to the imine bond, and the angle is twisted about $30^{\circ}$ by steric hindrance. On the other hand, the cis $C$-connected phenyl rings are rather perpendicular to the imine bond. (3) The cis $C$-connected phenyl rings at the terminals of the dendritic branch elongate toward the inside of the dendrimer. Molecular modeling of DPA G4 was performed according to the conformational rules. With increasing generation, the molecular structure of DPA was revealed to become three-dimensionally expanded due to the steric hindrance among the bulky branches (Fig. 3). As a result, a DPA G4 molecule was expected to have a sphere-like structure $(2.5 \times 2.9 \times 2.3 \mathrm{~nm})$ with four horns in the solid state. The size of a DPA G4 molecule was estimated based on the occupied area of the molecule in a monolayer on water in $\pi$-A measurement. The $\pi$-A isotherms of DPAs $\mathrm{G} 2-4$ showed a transition behavior on pure water. The DPA G4 curve rose with the limiting area of $3.8-4.2 \mathrm{~nm}^{2}$. The diameter of a DPA G4 molecule calculated from the area is $2.2-2.3 \mathrm{~nm}$, which agrees with the result of the molecular modeling.

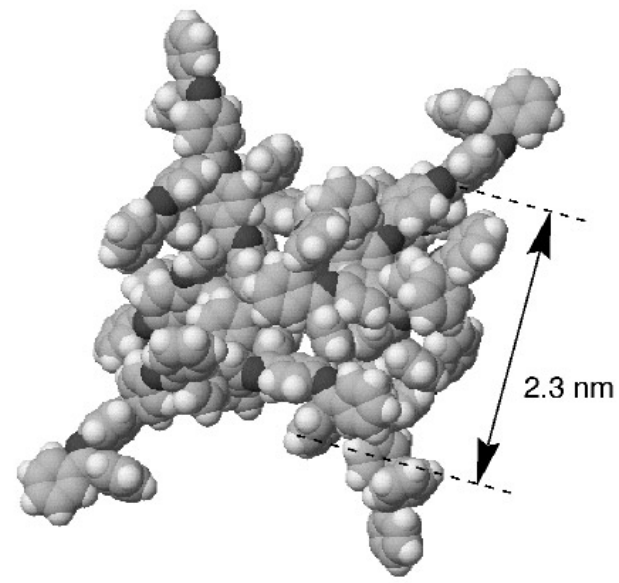

Fig. 3 Molecular model of DPA G4.

\section{MOLECULAR ASSEMBLING OF DPAS}

The sphere-like structure and the molecular assembling of DPA G4 were confirmed by transmission electron microscopy (TEM) and atomic force microscopy (AFM) measurements. The DPA G4 molecule was observed by TEM as a round shape with a $2.3 \pm 0.3-\mathrm{nm}$ diameter. The $2.3-\mathrm{nm}$ diameter is just in agreement with the result of the molecular modeling, but the size is much smaller than those of a similar generation of reported dendrimers consisting of a single bond backbone such as polyamide dendrimer (PAMAM) [9]. In general, the observed diameter of the dendrimers with a single bond backbone by TEM becomes much longer than expected, because the flexible conformation of the dendrimers causes the deformation of the molecule on a plate. In other words, the small diameter of a DPA G4 molecule shows a three-dimensionally expanded structure without deformation on a plate. However, TEM pictures give little information as to the height. Therefore, AFM measurements were performed in the noncontact mode in order to reveal the height of DPA G4 on a plate. DPA G4 molecules cast on a graphite plate were observed by AFM as a regularly assembled and multilayered packing structure [7b]. 
A lattice pattern was confirmed in the picture, and the cross-section clearly shows alignment of the spherical molecules in a multilayer, though the resolution is close to the limit in the tapping mode. The height of the DPA G4 molecule was estimated from the cross-section to be at least $2.0 \pm 0.1 \mathrm{~nm}$. The observed height will be smaller than the actual height of the dendrimer due to overlapping with the underlayer. Therefore, these results revealed that the DPA G4 molecules have a sphere-like structure with about a 2.3-nm diameter, which almost agreed with the result of the molecular modeling. Conformational rigidity of the $\pi$-conjugated backbone in DPA G4 enables the regular polymer-assembling on a plate without deformation of the molecule.

\section{STEPWISE RADIAL COMPLEXATION IN DPAS}

Imine nitrogen coordinates strongly to various metal ions, and is complexed with $\mathrm{SnCl}_{2}$ at the ratio of 1:1, because $\mathrm{SnCl}_{2}$ has one coordinating site. Therefore, DPA G4 having 30 imines should trap 30 equiv of $\mathrm{SnCl}_{2}$. Because the complexation accompanies a color change from yellow to orange, the complexation behavior can be monitored by UV-vis spectral measurement. During sequential addition of up to 30 equiv of $\mathrm{SnCl}_{2}$ to a dichloromethane/acetonitrile solution of DPA G4, four time changes in the position of the isosbestic point were observed in UV-vis spectra (Fig. 4). These phenomena indicate that the complexation proceeds not randomly, but stepwise. The spectral changes were finished within $10 \mathrm{~min}$ after addition of $\mathrm{SnCl}_{2}$. An isosbestic point appears when a compound is quantitatively trans-

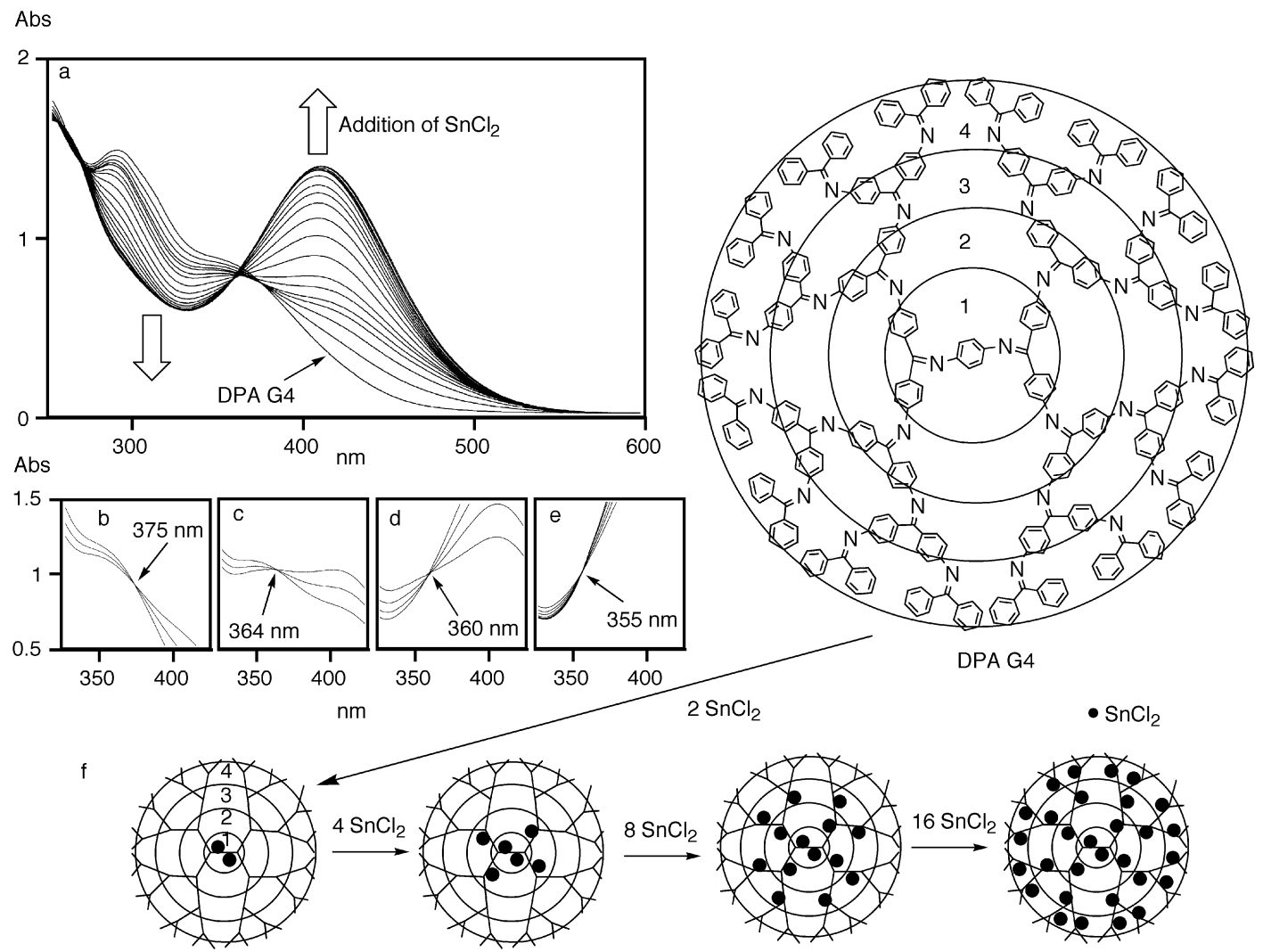

Fig. 4 UV-vis spectra of DPA G4 $\left(5 \times 10^{-6} \mathrm{M}\right)$ complexed with (a) 0-30, (b) 0-2, (c) 3-6, (d) 7-14, and (e) 15-30 equiv of $\mathrm{SnCl}_{2}$ (solv. 1:1 dechloromethane:acetonitrile), and (f) schematic representation of stepwise radial complexation of DPA G4 with $\mathrm{SnCl}_{2}$. 
formed into another by complexation, so the four shifts in the isosbestic point suggest that four different complexes are successively formed on $\mathrm{SnCl}_{2}$ addition.

The spectra of DPA G4 gradually changed, with an isosbestic point at $375 \mathrm{~nm}$ up to the addition of 2 equiv of $\mathrm{SnCl}_{2}$. The isosbestic point then shifted on further addition of $\mathrm{SnCl}_{2}$ and appeared at $364 \mathrm{~nm}$ between 3 and 6 equiv. While adding between 7 and 14 equiv of $\mathrm{SnCl}_{2}$, an isosbestic point appeared at $360 \mathrm{~nm}$, moving to $355 \mathrm{~nm}$ on adding between 15 and 30 equiv. Overall, the isosbestic point shifted about $20 \mathrm{~nm}$ from 375 to $355 \mathrm{~nm}$, and the number of added equivalents of $\mathrm{SnCl}_{2}$ required to induce a shift was in agreement with the number of imine sites present in the different shells of DPA G4. From a kinetic standpoint, complexation of the terminal imines of the dendrimer is expected to occur first. However, the titration results suggest that, on the timescale of our observations, the process is thermodynamically controlled and proceeds in a stepwise fashion from the core imines to the terminal imines of DPA G4.

Similar stepwise complexation was also observed with DPAs G2 and G3 (Fig. 5). For DPA G2, two isosbestic points appeared at 344 and $355 \mathrm{~nm}$ on adding 0-2 and 3-6 equiv of $\mathrm{SnCl}_{2}$, respectively. For DPA G3, three isosbestic points appeared at 367, 360, and $355 \mathrm{~nm}$ on adding between $0-2,3-6$, and 7-14 equiv of $\mathrm{SnCl}_{2}$, respectively. Again, the equivalents of $\mathrm{SnCl}_{2}$ added before a shift in isosbestic point is observed agree with the number of imine sites present in the different shells of the two dendrimers. These results further supported the idea that metal ions are incorporated in a stepwise fashion, filling first the shell close to the dendrimer core and then progressively the more peripheral shells.

A shell-selective reduction (SSR) method for imines in DPAs was exploited as a novel method to confirm the stepwise complexation except for UV-vis spectral measurements. This method is based on the reduction of imines to amines accelerated by complexation with $\mathrm{SnCl}_{2}$. Because only the imine groups complexed with $\mathrm{SnCl}_{2}$ in DPAs are reduced during the reduction of the complexes, the positions of $\mathrm{SnCl}_{2}$ molecules in the DPA complexes are exactly determined by identification of the product after reduction of the complex. The two imine sites of DPA G1 were quickly and quantitatively reduced to amines during the reduction complexed with 2 equiv of $\mathrm{SnCl}_{2}$ in the presence of $\mathrm{NaBH}_{4}$. Using this reduction method, only two imines at the $1^{\text {st }}$ shell were selectively reduced to amines (DPA-red G2, a $90 \%$ NMR yield) during the reduction of DPA G2 complexed with 2 equiv of $\mathrm{SnCl}_{2}$. This result clearly supports the idea that 2 equiv of $\mathrm{SnCl}_{2}$ are complexed with the two imines of the $1^{\text {st }}$ shell in DPA G2. DPA-red G2 was assigned by NMR and MS measurements. In the ${ }^{1} \mathrm{H}$ NMR spectrum of DPA G2, two pairs of doublet peaks attributed to the $1^{\text {st }}$ shell of the $C$-connected phenyl rings appear based on the cis- or trans-conformation for the core phenyl ring. On the other hand, in the spectrum of DPA-red G2, only one pair of doublet peaks attributed to the $C$-connected phenyl rings appears due to the disappearance of the regio-conformation, and one pair of doublet peaks attributed to the reduced imines appears around $5.2 \mathrm{ppm}$. The TOF-MS spectrum is also useful in determining the positions of the amine groups in DPA-red G2, because the fragment peak based on easy cleavage of the $\mathrm{C}-\mathrm{N}$ single bond appears in the spectrum. In the spectrum of DPA-red G2, the fragment peak at 524.2 shows the cleavage of the $\mathrm{C}-\mathrm{N}$ single bond at the $1^{\text {st }}$ shell. 

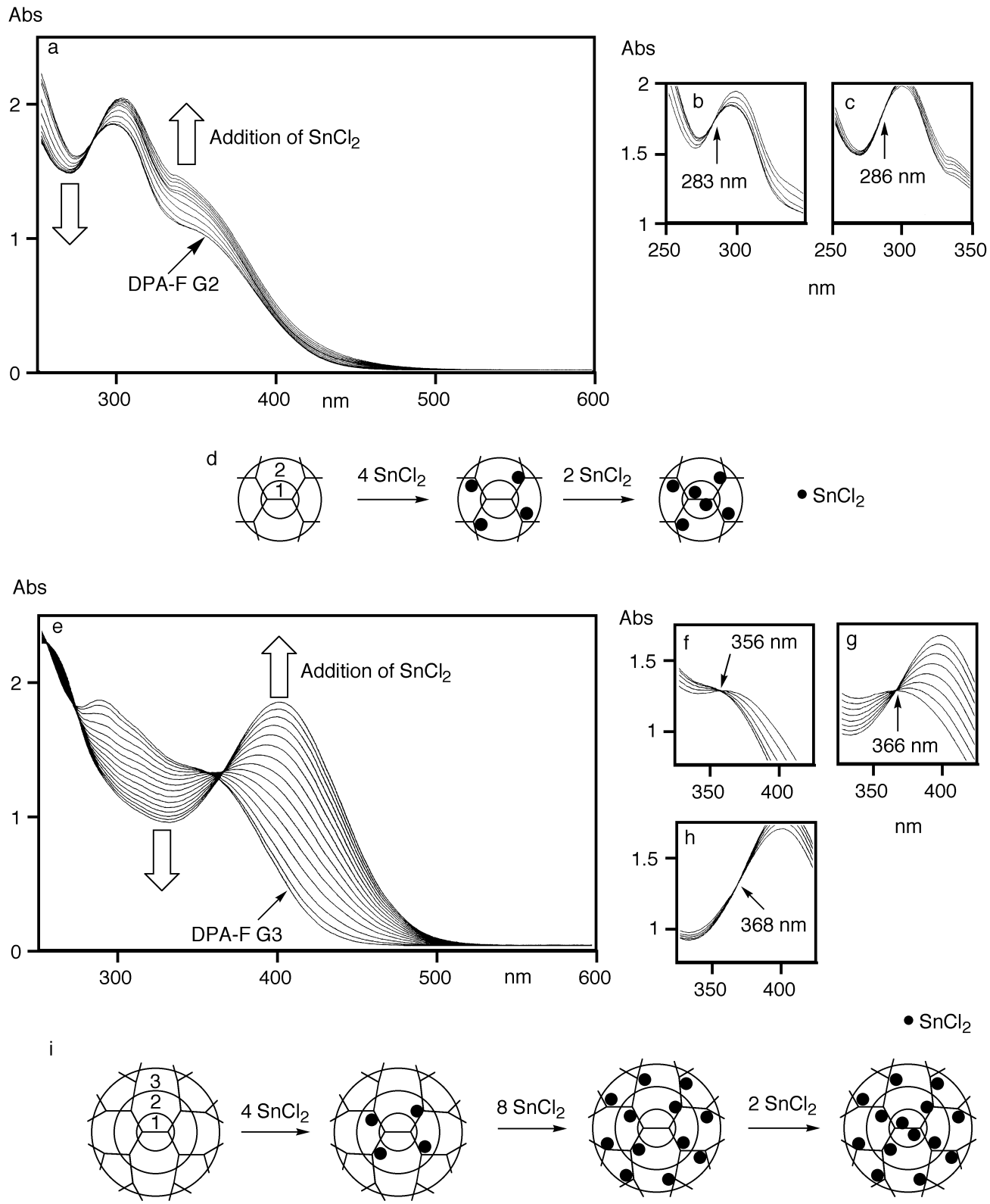

$2 \mathrm{SnCl}_{2}$

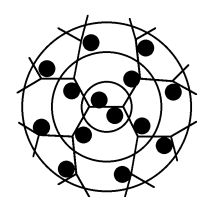

Fig. 5 UV-vis spectra of DPA G2 $\left(3 \times 10^{-5} \mathrm{M}\right)$ complexed with (a) 0-6, (b) 0-2, and (c) 3-6 equiv of $\mathrm{SnCl}_{2}$ ( $\mathrm{Solv}_{\text {. }}$ 1:1 dechloromethane:acetonitrile), and (d) schematic representation of stepwise radial complexation of DPA G2 with $\mathrm{SnCl}_{2}$. UV-vis spectra of DPA G3 $\left(1 \times 10^{-5} \mathrm{M}\right)$ complexed with (e) 0-14, (f) 0-2, (g) 3-6, and (h) 7-14 equiv of $\mathrm{SnCl}_{2}$ (solv. 1:1 dechloromethane:acetonitrile), and (i) schematic representation of stepwise radial complexation of DPA G3 with $\mathrm{SnCl}_{2}$. 


\section{CONCLUSION}

For the development of organic-metallic hybrid nanomaterials, it becomes very important to control the number and position of metal ions in the polymer complexes. DPAs were exploited as novel $\pi$-cojugated polymer ligands with a single molecular weight and a clearly defined structure. DPAs were synthesized by the convergent method via dehydration of aromatic ketones with aromatic amines in the presence of $\mathrm{TiCl}_{4}$, and showed a high solubility and high thermal stability. Based on the conformational rigidity of the $\pi$-conjugated backbone, DPA G4 molecule was revealed to have a sphere-like structure (diameter: $2.3 \mathrm{~nm}$ ) and is regularly assembled on a plate without deformation by means of X-ray crystal analysis, a molecular model, GPC, TEM, AFM, and $\pi$-A measurements. The stepwise complexation was observed in DPAs as stepwise shifts of the isosbestic point in the UV-vis spectra. DPA G4 has 2, 4,8 , and 16 imine groups in the $1^{\text {st }}, 2^{\text {nd }}, 3^{\text {rd }}$ and $4^{\text {th }}$ shells, respectively (total, 30 imine groups). DPA G4 can trap 30 equiv of $\mathrm{SnCl}_{2}$ molecules, because the imine group is complexed with $\mathrm{SnCl}_{2}$ at a ratio of 1:1. During addition of 30 equiv of $\mathrm{SnCl}_{2}$ to DPA G4, four shifts in the isosbestic point were observed in the UV-vis spectra, and the amount of $\mathrm{SnCl}_{2}$ added in each step is in agreement with the number of the imine groups in each shell of DPA G4. This result shows that the complexation of the imine groups in DPA G4 with $\mathrm{SnCl}_{2}$ occurs stepwise in the order of the $1^{\text {st }}, 2^{\text {nd }}, 3^{\text {rd }}$, and $4^{\text {th }}$ shells. The stepwise complexation was supported by a novel SSR method for imines. The precise metal-assembling of metal ions was first achieved in DPAs based on the unique stepwise complexation behavior.

\section{ACKNOWLEDGMENT}

This work was partially supported by CREST from Japan Science and Technology Agency (JST), Grants-in-Aid for Scientific Research (No. 15350073) and the $21^{\text {st }}$ COE Program (Keio-LCC) from the Ministry of Education, Science, Culture and Sports (MEXT), and a Research Grant (Project No. 23) from Kanagawa Academy of Science \& Technology (KAST).

\section{REFERENCES}

1. (a) C. Q. Liu, J. B. Lambert, L. Fu. J. Am. Chem. Soc. 125, 6452 (2003); (b) S. Inagaki, S. Guan, T. Ohsuna, O. Terasaki. Nature 416, 304 (2002); (c) Y. F. Lu, Y. Yang, A. Sellinger, M. C. Lu, J. M. Huang, H. Y. Fan, R. Haddad, G. Lopez, A. R. Burns, D. Y. Sasaki, J. Shelnutt, C. J. Brinker. Nature 410, 913 (2001); (d) E. Coronado, J. R. Galan-Mascaros, C. J. Gomez-Garcia, V. Laukhin. Nature 408, 447 (2000).

2. (a) "Supramolecular Polymers", A. Ciferri and M. Dekker (Eds.), New York (2000); (b) "Dendrimer I, II, III", F. Vögtle (Ed.), Springer, New York (2001); (c) "Dendrimer and Dendrons", G. R. Newkome, C. N. Moorefield, F. Vögtle (Eds.), Wiley-VCH, New York (2001); (d) D. A. Tomalia, J. Dewald, M. Hall, S. Martin, P. B. Smith. Prepr. SPSJ Int. Polym. Conf., $1^{\text {st }}$ 65 (1984); (e) D. A. Tomalia, H. Baker, J. R. Dewald. Polym. J. 17, 117 (1985); (f) G. R. Newkome, Z. Q. Yao, G. R. Baker, V. K. Gupta. J. Org. Chem. 50, 2003 (1985).

3. (a) C. Devadoss, P. Bharathi, J. S. Moore. J. Am. Chem. Soc. 118, 9635 (1996); (b) D. L. Jiang and T. Aida. Nature 388, 454 (1997); (c) T. D. Selby and S. C. Blackstock. J. Am. Chem. Soc. 120, 12155 (1998).

4. (a) R. M. Crooks, M. Zhao, L. Sun, V. Chechik, L. K. Yeung. Accounts Chem. Res. 34, 181 (2001); (b) M. Petrucci-Samija, V. Guillemette, M. Dasgupta, A. K. Kakkar. J. Am. Chem. Soc. 121, 1968 (1999); (c) M. Kawa and J. M. J. Fréchet. Chem. Mater. 10, 286 (1998); (d) G. R. Newkome, E. He, C. N. Moorefield. Chem. Rev. 99, 1689 (1999); (e) D. Astruc and F. Chardac. Chem. Rev. 101, 2991 (2001); (f) V. Balzani, P. Ceroni, A. Juris, M. Venturi, S. Campagna, F. Puntoriero, S. Serroni. Coord. Chem. Rev. 219, 545 (2001). 
5. (a) Handbook of Organic Conductive Molecules and Polymers, H. S. Nalwa (Ed.), Vols. 1-5, Wiley-VCH, New York (1997); (b) K. Yamamoto, M. Higuchi, H. Takai, T. Nishiumi. Org. Lett. 3, 131 (2001); (c) T. Nishiumi, M. Higuchi, K. Yamamoto. Macromolecules 36, 6325 (2003); (d) M. Higuchi, D. Imoda, T. Hirao. Macromolecules 29, 8277 (1996); (e) M. Higuchi, I. Ikeda, T. Hirao. J. Org. Chem. 62, 1072 (1997).

6. (a) R. Adams, R. E. Bullock, W. C. Wilson. J. Am. Chem. Soc. 45, 521 (1923); (b) C. S. Marvel and N. W. Hill. J. Am. Chem. Soc. 72, 4819 (1950); (c) C. S. Marvel and N. Tarköy. J. Am. Chem. Soc. 79, 6000 (1957); (d) L. G. Kaufman, P. T. Funke, A. A. Volpe. Polym. Prepr. (Am. Chem. Soc. Div. Polym. Chem.) 11, 250 (1970); (e) K. Suematsu, K. Nakamura, J. Takada. Polym. J. 15, 71 (1983); (f) P. W. Morgan, S. L. Kwolek, T. C. Pletcher. Macromolecules 20, 729 (1987); (g) C. J. Yang and S. A. Jenekhe. Macromolecules 28, 1180 (1995); (h) O. Thomas, O. Inganäs, M. R. Andersson. Macromolecules 31, 2676 (1998).

7. (a) M. Higuchi, S. Shiki, K. Yamamoto. Org. Lett. 2, 3079 (2000); (b) M. Higuchi, S. Shiki, K. Ariga, K. Yamamoto. J. Am. Chem. Soc. 123, 4414 (2001); (c) K. Yamamoto, M. Higuchi, S. Shiki, M. Tsuruta, H. Chiba. Nature 415, 509 (2002); (d) M. Higuchi and K. Yamamoto. J. Syn. Org. Chem. Jpn. 60, 869 (2002); (e) M. Higuchi, M. Tsuruta, H. Chiba, S. Shiki, K. Yamamoto. J. Am. Chem. Soc. 125, 9988 (2003).

8. (a) M. Higuchi and K. Yamamoto. Org. Lett. 1, 1881 (1999); (b) M. Higuchi, A. Kimoto, S. Shiki, K. Yamamoto. J. Org. Chem. 65, 5680 (2000); (c) M. Higuchi, H. Kanazawa, M. Tsuruta, K. Yamamoto. Macromolecules 34, 8847 (2001); (d) M. Higuchi and K. Yamamoto. Polym. Adv. Technol. 13, 765 (2002); (e) M. Higuchi, H. Kanazawa, K. Yamamoto. Org. Lett. 5, 345 (2003).

9. M. Crooks and A. J. Ricco. J. Am. Chem. Soc. 120, 5323 (1998); (b) H. Tokuhisa, M. Zhao, L. A. Baker, V. T. Phan, D. L. Dermody, M. E. Garcia, R. F. Peez, R. M. Crooks, T. M. Mayer. J. Am. Chem. Soc. 120, 4492 (1998); (c) J. Li, D. R. Swanson, D. Qin, H. M. Brothers, L. T. Piehler, D. Tomalia, D. T. Meier. Langmuir 15, 7347 (1999). 